\title{
Can a medical need clause help manage the growing costs of prescription drugs in the
}

\section{EU?}

\begin{abstract}
Innovation in the development of new drugs has to balance the needs of health actors and administrators, the pharmaceutical industry and patients. Differing perspectives on what constitutes an innovation, where research and development should be directed and how new drugs should be evaluated and priced cause ongoing tensions within the regulatory framework. In current climate, where Europe’s health systems face rising demand for health services and increasingly restricted resources, the efficiency of pharmaceutical regulation and drug development is under even greater scrutiny. How can regulation foster innovation and industry growth whilst also serving the public health needs of society, and what is the EU's role in pursuing this objective? Drawing on a provision which formerly existed in Norwegian pharmaceutical legislation, this article explores the potential of a medical need clause in addressing these issues. In restricting market authorisations to those drugs which offer an added therapeutic value, might a medical need clause foster innovation and spending efficiency in Europe's health systems?
\end{abstract}

\section{Keywords}

- pharmaceuticals

- European Union

- innovation

- research

- regulation

\section{Introduction}


European health systems are in a continual state of regulatory tension with regards to drug needs and development. One of the most severe pressure points in this tension is the regulation and approval of new prescription drugs. For example, whereas the pharmaceutical industry views the creation of a new drug (or new molecular entity, NME) from a profit and market-oriented perspective, health organisations are under pressure to keep drug costs down and focus on the efficacy and safety of the drug, patients often want the latest new drug (often promoted via the media) to feel confident that they are getting the best care possible, while governments struggle to balance these competing interests and demands.

Is there a way to balance the needs of health actors, the pharmaceutical industry and patients regarding drug innovation and therapeutic advance? Or are European health systems condemned to oscillate between the varying perspectives? Moreover, what can the EU do about it?

This articles will explore whether part of the answer to these difficulties lies in the creation of a 'medical need clause' (MNC) that redirects pharmaceutical research and activities towards the creation of NMEs which respond to a clear medical need as defined by health actors, agencies and patients. Variants of medical need clauses have been used in the past and had a clear impact on both prescription drug usage and expenditure. This article briefly discusses the background of the current situation, examines the definition, function and technical challenges of the MNC, explores some of the EU and national attempts to create MNC-like regulatory policies, and discusses the potential for MNC development in the EU.

\section{Background}

Getting the balance right in health policy is a difficult, political and continual process. In the field of prescription drug policy the balance in Europe has increasingly tipped in favour of a more market-oriented approach which has downplayed the importance of comparative 
efficacy and patient need. In 2001, a meeting of the International Society of Drug Bulletins (ISDB) drafted a Declaration on therapeutic advance in the use of new drugs. It stated that pharmaceutical regulation, conflating technological innovation with increased efficacy, does not take sufficient account of the added therapeutic value (ATV) of the medicines it assesses (ISDB, 2001: 1). Subsequent analysis noted that much of European pharmaceutical legislation was developed in the aftermath of the Thalidomide tragedy and consequently focuses primarily upon drug safety and, more recently, pharmacovigilance and adverse reaction reporting. New drugs must prove they have an acceptable risk-benefit balance but are not required to be compared to the prevailing alternative; comparative benefit, if a priority at all, is of secondary concern [6] (Wieseler, 2011: 2).

In their recent article, Light and Lexchin (2012: 1) contend that, whilst the pharmaceutical industry insists that it is suffering from an 'innovation crisis’ characterised by declining returns on research and development $(\mathrm{R} \& \mathrm{D})$ investment, the 'real innovation crisis' lies in the lack of new drugs which have ATV. They argue that the measure of innovation preferred by the pharmaceutical industry and claimed to be in decline, has, in fact, been relatively stable since the mid-1990s. What has declined, Light and Lexchin note, is the approval of drugs which offer clinical advantages over those already on the market. This position was supported by a 2002 report in La Revue Prescrire which found that of the new drugs and indications approved in France between 1981 and 2001, only 12 per cent represented a therapeutic advance (La Revue Prescrire, 2002: 58). By 2012, that figure had fallen to just eight per cent, whilst nearly 16 per cent were judged to be more harmful than beneficial (La Revue Prescrire, 2012: 107). Further studies have shown the ratio of industry investment in R\&D to expenditure on marketing to be 1:19, revealing a 'hidden business model' whereby minor variations on existing drugs are focused on and fiercely marketed to encourage prescription and consumption (Light and Lexchin, 2012: 2). These drugs are trialled on patients with little 
prospect of significant therapeutic advance and often against control groups administering a placebo (Wemos, 2013). The global price pursued by pharmaceutical companies is now commonly challenged by governments - see, for example, the two year moratorium and 'claw back' mechanisms introduced in the UK's Pharmaceutical Price Regulation Scheme (Wise, 2013). It is also increasingly negotiated to reflect national circumstance, as in the case of Sofosbufir, a 'blockbuster' hepatitis C drug which has been allocated country-specific pricing based on GDP per capita (Raftery, 2014). These downward pressures on price are certainly increasing in the prevailing financial climate, but the fundamental interest of the industry remains in manufacturing drugs which offer the most attractive profit margin and return on investment [4].

Despite the absence of clinical superiority, expenditure on pharmaceuticals comprises a significant proportion of government health budgets, accounting for an average 17 per cent of health expenditure across OECD (Organisation for Economic Cooperatio and Development) countries in 2011 and increasing by almost 50 per cent in real terms since 2000 (OECD, 2013: 160; OECD, 2011: 154) [1]. Public funds for healthcare are therefore increasingly stretched by rising pharmaceutical expenditure, whilst public money is used to fund more than four-fifths of research to discover new medicines worldwide [7] [8] (Light and Lexchin, 2012: 2). Thus, pharmaceutical development in Europe has reached a point where public money is being used for the development of drugs which offer little clinical advantage and are a drain on the financial resources of national health systems. But is a medical need clause part of the answer?

\section{What is a MNC? The Norwegian Model}

A MNC might take many forms and be designed in a number of ways, but it can be explained by reference to its earlier configuration in Norwegian pharmaceutical law. The Norwegian 
MNC ('behovsparagraf') stated that, 'only products which are needed will be allowed on the Norwegian market' and allowed the national authority to limit the number of products available, 'based on the philosophy that a smaller number of rationally chosen drugs would be easier to manage and more effective. The authorities could insist that new drugs had a better benefit-risk ratio than those already on the market' (Norris, 1998: 69).

Whilst in place, the Clause resulted in a smaller market and reduced pharmaceutical expenditure (Håkonsen et al., 2009: 278). For example, between 1981 and 1983 the MNC enabled Norwegian authorities to reject 40 per cent of applications for market authorisation, citing the MNC in 60 per cent of these decisions, and limited the number of drugs on the market to around 2,200, compared with a range of 7,000 to 25,000 in non-Nordic European countries (Andrew et al., 1995: 46; Jøldal, 1986: 665). However, upon joining the European Economic Area (EEA) in 1994, Norway was forced to abandon its MNC in order to comply with the dominant regulatory framework in Europe. The resulting growth in the size of the drug market was less than feared but still led to some problematic drug usage and care outcomes (Brooks and Geyer, 2015 and Lu et al., 2011: 17), [2].

As such, the aim of a MNC is to stop products which have no ATV from coming onto the market, by requiring that new drugs demonstrate such ATV, constitute a therapeutic advance or are clinically superior to existing alternatives. These terms are used interchangeably in the literature and embody roughly the same notion - that new drugs are not automatically an improvement on existing treatments. The extent of a new medicine's improvement should be measured according to the added value for the patient, the healthcare system and society as a whole derived from consuming the new drug instead of the older alternative.

\section{What might be the goal of a MNC?}


In preventing unnecessary or less innovative medicines from coming onto the market, a MNC might serve a number of purposes.

From a health systems perspective, a MNC should help to control the level of pharmaceutical spending within a health system by limiting the development of so-called 'me-too drugs' drugs that are 'minor variations of drugs already on the market (Angell, 2004: 21) and which consume R\&D resources and diminish incentives for innovation (Hollis, 2004: 1). It can be argued that allowing me-too drugs, and therefore encouraging competition and duplication within the same therapeutic class of medicine, might increase doctor and patient choice, offer a drug more easily tolerated by certain groups of patients, or even reduce expenditure by encouraging price competition (Garattini, 1997). However, when these drugs are brought onto the market and heavily promoted as the originator drug goes 'off patent', the potential to increase consumption of the more expensive me-too drug is likely to outweigh potential cost benefits (Morgan et al., 2005) [26]. By encouraging the creation of a regulatory environment where it is less profitable to develop drugs that are unlikely to be therapeutic advances, socially responsible (rather than market-oriented) research and innovation would be incentivised (Nathan, 2007: 304).

There are also ethical considerations, such as reducing the number of unnecessary clinical trials (Garattini and Bertele, 2007; Light et al., 2013: 9; Simon, 2000: 1). Moreover, a MNC might also go some way to addressing the ethics of using public money to fund research which does not lead to a clinically superior innovation. In the current system, most R\&D money is spent developing drugs which are molecularly different but therapeutically similar, but this would seem to be an inefficient use of public health resources (Light and Lexchin, 2012: 2; 2013: 4).

\section{Technical challenges when defining and measuring the value of new drugs}


Central to the design and effective implementation of a MNC are the definitions given to 'therapeutic advance' and 'medical need'.

Following in the footsteps of the ISDB, we define 'therapeutic advance' as more than just product innovation. As the ISDB argues, the term innovation covers three concepts: the commercial concept of any newly-marketed me-too product; the technological concept of any industrial innovation, for example in biotechnology; and the concept of therapeutic advance 'a new treatment that benefits the patient when compared to previously existing options' (ISDB, 2001: 1). This understanding encourages the identification of therapeutic advance as a separate value by, as the ISDB states, assessing the efficacy, safety and convenience of all new drugs, and considering these values in the broader context of cost and quality (ISDB, 2001: 2; Wieseler, 2011: 1).

Therapeutic advance is also commonly embodied in the term 'clinically superior'. The United States Food and Drug Administration (US FDA) defines clinically superior drugs as those which are 'shown to provide a significant therapeutic advantage over and above that provided by an approved...drug ${ }^{1}$. Similarly, within the EU framework, Regulation 847/2000 on orphan drugs defines such medicines as those which provide a 'significant therapeutic or diagnostic advantage over and above that provided by an authorised orphan medicinal product $^{\text {,2 }}$. It goes on to provide that such advantage might be demonstrated in 'greater efficacy than an authorised orphan medicinal product', noting that 'direct comparative clinical trials are generally necessary ${ }^{3}$.

As shown, when determining therapeutic advance, a regulatory body might take into account a range of factors. In addition to those mentioned above, these might also include [9]: patient

\footnotetext{
${ }^{1}$ US FDA CFR Title $21 \S 316.3$.

${ }^{2}$ OJ 2000 L 103/5 28.4.2000.

${ }^{3}$ Ibid. Article 3(d)(1).
} 
convenience, encompassing changes in the administrative route of a given drug; societal impact, for example where a drug tackles social challenges such as alcoholism; health systems impact, to put pharmaceutical spending in the context of health system financing and sustainability; individual impact, balancing the gains of individual affected patients against the opportunity cost of procuring a drug and; comparative effectiveness, requiring all drugs to be compared to the existing or next best alternatives.

Medical need builds on the notion of therapeutic advance, reflecting the public interest in medicines which treat the health scourges of modern society and improve the health outcomes of the population at large. Though definitions of the two concepts are interrelated, medical need can be considered a broader concept, embodying societal need as well as clinical benefit [10].

Though a MNC does not currently exist in Europe, tools for classifying drugs according to their therapeutic value have been developed by some medicines agencies and by journals such as Prescrire (Vitry et al., 2013: 2). Some examples also exist at member state level and the Italian case is briefly elaborated below by way of illustration [11].

\section{The Italian Model}

The model used by the Italian Medicines Agency (AIFA) to decide upon qualification for the reimbursement system first divides new drugs into three categories according to therapeutic target - those aimed at serious diseases (such as cancer), those aimed at risk factors for serious disease (such as hypertension) and those aimed at non-serious diseases (such as allergic rhinitis) (AIFA, 2007: 2). Once a severity class has been assigned, each drug is assessed on two criteria: 1) the availability of existing treatments, ranging from none currently available, to some resistant subgroups, to treatments already exist, and 2) the extent of the therapeutic effect, ranging from greater benefit, to partial benefit, to minor or 
temporary benefit (AIFA, 2007: 3). The degree of innovation of a new drug is established by a combination of scores and weightings which ensure that the label 'innovative' is only assigned to those medicines which offer the patient additional therapeutic benefits in relation to those already available. These are drugs which are considered to fulfil a medical need and serve the public interest.

\section{How might a MNC fit into EU level market authorisation policy?}

The law and regulatory policy governing pharmaceuticals in Europe is a multi-level interaction of national, EU and international practices and principles (Abraham and Lewis, 2000: 95; Hancher, 1990: 10; Hervey and McHale, 2004: 286). At the EU level, some MNCstyle elements are already embodied in market authorisation regulation, where the EU has a strong competence.

Market authorisation of medicinal products for human use

Pharmaceutical companies which wish to put a product on the market of an EU member state must first obtain a market authorisation. There are two types of authorisation in the EU community authorisations, which are issued by the Commission (support by the European Medicines Agency EMA) for the entire territory via the 'centralised procedure', and national authorisations, which are issued by national competent authorities. In 2013, the EMA gave positive opinions on 79 out of 86 applications for market authorisation via the centralised procedure, compared with 57 out of 68 in 2012 (EMA, 2015) [12].

[13] The amended Directive 2001/83/EC on the Community code relating to medicinal products consolidates and clarifies the provisions relating to authorisations via the mutual recognition procedure (MRP). This is used where an authorisation has already been granted in one member state and the company wishes to market the product in other member states 
without submitting identical applications. Article 26 states that authorisation shall be refused if:

'(a) The risk-benefit balance is not considered to be favourable; or

(b) Its therapeutic efficacy is insufficiently substantiated by the applicant; or

(c) Its qualitative and quantitative composition is not as declared. ${ }^{4}$

Whilst therapeutic efficacy must be demonstrated by the pharmaceutical company, it is not required to be of any given advantage or improvement on existing treatment.

Regulation $726 / 2004^{5}$ gives more detailed and specific guidance on the market authorisation processes and establishes the centralised (Community) authorisation procedure. Centralised authorisations are compulsory only for certain types of drugs. Currently, these include:

'orphan medicinal products and any medicinal product for human use containing an entirely new active substance...for which the therapeutic indication is the treatment of acquired immune deficiency syndrome, cancer, neurodegenerative disorder or diabetes...also...products... for which the therapeutic indication is for the treatment of autoimmune diseases and other immune dysfunctions and viral diseases. ${ }^{6}$

The following paragraph makes the Community procedure optional for medicinal products which:

'...although not belonging to the abovementioned categories, are nevertheless therapeutically innovative. It is also appropriate to allow access to this procedure for medicinal products

\footnotetext{
${ }^{4}$ Directive 2001/83/EC Article 26(1).

${ }^{5}$ Regulation (EC) 726/2004.

${ }^{6}$ Ibid.: point 8.
} 
which, although not innovative, may be of benefit to society or to patients if they are authorised from the outset at Community level. ${ }^{7}$

Similarly, a medicinal product may be granted an authorisation if 'the medicinal product constitutes a significant therapeutic, scientific or technical innovation or...is in the interests of patients... at Community level ${ }^{8}$. Furthermore, Regulation (EC) 507/2006 ${ }^{9}$ recognises that if there is an 'unmet medical need' and the a product provides a major therapeutic advantage then the EU may grant marketing authorisations on the basis of less complete data and subject to specific 'conditional marketing authorisations' ${ }^{1011}$.

These excerpts demonstrate that some notion of medical need is already embodied in EU pharmaceutical policy. Drugs which target certain categories of diseases, in particular those representing some of the greatest scourges on European health systems, are given priority on the basis that they are 'worth more'. Similarly, the idea that new drugs might be 'in the interest' of patients or of value to society is explicitly referenced - existing legislation prioritises drugs fulfilling these criteria only in the context of the centralised procedure, but by institutionalising such categories lays the foundations for their potential operation in other parts of the legislative framework [14] [16].

\section{Conclusions from the EU level: a feasible role for a MNC?}

As mentioned above, the EU has already legislated concepts of 'therapeutic efficacy', 'riskbenefit balance' and a centralised structure for encouraging 'therapeutically innovative' or 'socially beneficial' health technologies. It even has concepts of 'medical need'. In other

\footnotetext{
${ }^{7}$ Ibid.: point 9.

${ }^{8}$ Ibid.: Article 3(2).

${ }^{9}$ OJ 2006 L 92/6 30.3.2006.

${ }^{10}$ Ibid.: Recital 2.

${ }^{11}$ Ibid.: Article 4(2).
} 
areas, such as clinical trials and orphan drug regulation, concepts of a comparative, 'significant therapeutic or diagnostic advantage over and above that provided by an authorised...product ${ }^{, 12}$ have also been introduced. [17] However, despite all of these developments, establishing a MNC remains a politically fraught process. Attempts to establish MNC-like regulations in clinic trials have been blocked on several occasions within the European Parliament (Garattini and Bertele, 2004: 89). [18] The earlier Clinical Trials Directive, for instance, promisingly stated that trials could only be conducted if anticipated therapeutic benefit outweighed risk but this provision failed to stem the proliferation of trials for me-too drugs and might even be argued to have encouraged production of drugs within the same, pre-tested therapeutic area [18]. In 2014 a new Clinical Trials Regulation was adopted - though, on balance, it weakened the role of therapeutic value, during the legislative process a number of amendments posed contained elements of MNC- and ATV-related ideas, indicating continued political support for these concepts (Garattini and Bertele, 2004: 89) ${ }^{13}$. [3]

\section{How might a MNC fit into national level pricing and reimbursement policy?}

The EU governs a substantial portion of pharmaceutical regulation but does not have exclusive control. It is implicit in Article 168 of the Treaty on the Functioning of the EU (TFEU) [19] that national health policy in those matters covered by the Treaty cannot develop along totally separate national lines, but that some elements of multi-level coordination are required (Hervey, 2001: 1). Moreover, the core area of financing and organisation remains a national competence - for pharmaceuticals, this is most crucially reflected in the regulation of pricing and reimbursement, where some elements of a MNC can also be seen.

\footnotetext{
12 OJ 2000 L 103/5 28.4.2000; Article 3(d)

${ }^{13}$ OJ 2014 L 158/16 27.5.2014.
} 
A 2007 report by the Pharmaceutical Forum found that assessment methods amongst member states remain very different, with each having developed its own model for evaluating the therapeutic value of new drugs and taking account of this in the setting of drug prices (European Commission, 2007: 6). The report identified two main approaches:

'In some countries... prices are freely set upfront by the applying companies. The set price is then one of the input factors for the assessments that follow...In other countries the process starts with an upfront assessment... which in first place focuses on therapeutic/clinical benefits. This assessment is the basis for fixing prices'. [20]

The report concludes that many member states offer fast-track procedures for medicines considered to bring ATV and that in both of the approaches identified above, where therapeutic value is identified, 'a price premium versus comparator products can be allowed and reimbursed. The assessments are usually used to define the size of this price premium'. In recent years, value-based pricing (VBP) has emerged as a more transparent and comprehensive way of determining the price at which drugs should be purchased within a given health system. In essence, VBP equates value in health to the health outcome achieved per euro (or relevant currency) spent on the intervention employed. Furthermore, a recent European Parliament study on access to and costs of pharmaceuticals also recommends that VBP be incorporated into the reimbursement schemes at member state and, where applicable, EU level (European Parliament, 2011: 72).

Drug prices are currently published by pharmaceutical companies, using calculations based on the US market. Since drug companies are keen to maintain the same prices in all countries, to avoid parallel importing, this system automatically out-prices governments in less developed countries, and puts pressure on the healthcare budgets of any countries with a lower income per head than the US (which is all bar Norway, Switzerland and Luxembourg). 
In response to this unsustainable practice, governments have sought to encourage generics, establish price controls and, more recently, move towards a model of clinical and cost effectiveness assessment (Raftery, 2013: 1). The UK was, until recently, leading the way in the development of a VBP model to take account of the social benefits of drugs, such as the relief on the burden of carers (Hawkes, 2014; Raftery, 2013). However, the system is currently stalled, pending consensus among the parties involved [5].

A recent study on the definition of 'value' in 14 member countries of the OECD found that the way in which value is determined differs markedly between states. Of particular relevance is whether or not the country uses economic evaluation - those that do (such as Sweden, Norway and the UK) tend also to take account of patient utility, whereas those who do not (such as Italy and France) tend not to consider it (Paris and Belloni, 2013: point 147). The report also found that, in practice, wider social perspectives are often not taken into account, with the exception of the Swedish system and that most countries use VBP as a way of encouraging innovation (Paris and Belloni, 2013: point150). Fundamentally, the conclusions reached suggest that it is not yet possible to determine the impact that VBP is having, but that 'the practice of VBP often appears to be more of an art than a science' and that this could be damaging to the encouragement of true innovation (Paris and Belloni, 2013: 157).

\section{Examples from the national level: the German case}

[21] [22] [23] The German pharmaceutical market has historically been seen as an early launch market, but the reforms enacted in 2011 have cast uncertainty on this position. The pricing and reimbursement system within the German healthcare reform - AMNOG imposes substantial change upon the pharmaceutical industry, favouring innovative medicines producers and putting a greater focus on evidence-based medicine. The new parameters impact significantly on the potential pricing of medicines. Whereas companies 
used to set the price of drugs freely, this price is now subject to negotiation if the regulatory authority finds the drug to be worth less [24]. Drugs that are considered to have a therapeutic benefit - receiving a score of one to four - will be accepted for price-negotiation, meaning that the pharmaceutical company may secure a price premium above that of the relevant therapeutic alternative. Meanwhile, drugs which are rated five or six on the scale will not qualify for negotiation and the company must accept the price offered by the German reference-pricing system. Implementation of the AMNOG is underway - preliminary data reveals that in the 78 judgements made in the period to September 2013, 1 per cent of the drugs evaluated had less benefit than existing treatments, 55 per cent offered no additional benefit, 24 per cent provided minor additional benefit and 12 per cent had considerable additional benefit; no drugs were found to offer a major benefit to patients (Buko Pharma, 2013: 7).

\section{Conclusions from the national level: a feasible role for a MNC?}

Similar to the EU, there are a number of aspects that clearly link to some form of MNC.

National systems of pricing and reimbursement are evaluating and comparing the clinical and therapeutic value of drugs in order to determine their price, reimbursement level and/or inclusion on a recommended list of drug products. Value based pricing represents the latest development of this trend. Moreover, many states are actively fast-tracking drugs that are identified has having ‘significant added therapeutic value’ through the regulatory process. Furthermore, similar to actions at the EU level, some member states are also willing to give a 'price premium' to stimulate the development of these drugs. Hence, though there is obvious variety at the national level, the general regulatory tendency towards greater openness of data, increased comparative analysis, improved balancing between ATV and price and growing use of VBP shows that there is a surprising degree of convergence between the EU and member state levels. 


\section{General Conclusion and Implications: what role for a MNC in Europe?}

In examining the academic literature and legislative framework concerning a potential EU MNC, a number of interesting aspects emerge:

Despite the remarkable diversity of EU and national legislation, there seems to be a growing convergence within the EU and member state regulation towards various forms of MNC-type provisions and policies. This is clearly evident at the EU level and from the small selection of member state provision explored. A full exploration of member state regulation would be necessary to confirm this.

Though often seen as a form of 'negative' regulation inhibiting the development of noninnovative 'me-too' drugs (as in the Norway case above), much of the existing EU regulation is actually 'positive' regulation - attempting to stimulate the activities of the pharmaceutical industry towards more therapeutically valuable research, innovation and development activities. This is particularly true at the EU level where the 'carrot' of one unified regulatory mechanism for the entire EU can be used to stimulate the development of new therapeutically innovative and socially beneficial drug products. In addition, at the national level, the use of 'premium pricing' arrangements would obviously have a stimulating effect as well. Hence, one must view the creation of a new EU MNC as a 'carrot and stick' approach to pharmaceutical regulation.

For the foreseeable future, due to continual technological changes, innovations and the need to regulate them, the arena of drug regulation at the EU and national levels will continue to be a politically divisive and difficult one, pitting economically-concentrated interests against large scale public actors (national health systems), patient interest groups and the needs of society as a whole. A MNC will do little to resolve this fundamental tension. In general, using James Q. Wilson’s classic definitions of regulatory politics (Wilson, 1980), European 
drug regulation policy exhibits elements of both entrepreneurial politics, where the costs of regulation are concentrated on the pharmaceutical industry (inability to make profits from ‘me-too’ drugs, greater advertising activity, etc.) but the benefits are diffused throughout society (healthier drug usage and better health outcomes), and interest group politics, where the costs and benefits of regulation are concentrated and large political/economic actors have a great deal at stake (the pharmaceutical industry versus national health system actors, for example).

It is this combination of interests and actors which defines the policy process in pharmaceuticals, giving the Commission and the industry lobby primacy. With regard to a MNC, the focus on larger societal health needs and the bringing together of diffuse strands of EU drug regulation policy are clearly a way of strengthening the public voice in EU health policy and it is no surprise that MNC-style provisions are being advocated by an increasing number of entrepreneurial EU public health organisations (Wemos, 2013) [25].

The final questions to ask are, how would it be implemented and will it work? As discussed in the introduction, EU pharmaceutical legislation forms the central hub of regulation and governance in drug development, but it must operate in accordance with the broader EU principles (free movement, competition, etc.), must respect national competence, particularly in the areas of pricing and reimbursement, and must balance with related policy areas (single market, patents, etc.). Hence, a European MNC could take a variety of forms and be linked in to a range of policy areas. For example, a MNC could be introduced as part of most of the legislative provisions concerning pharmaceuticals. At the point of market authorisation, as in the Norwegian model, it could be contained within Directive 2001/83/EC and Regulation 726/2004, providing an additional requirement which new drugs must satisfy and demonstrate their fulfilment of in order to be marketed in the EU. A review of how innovation is defined in pharmaceutical regulation and policy could achieve many of the 
goals of a MNC, as could a provision stating that public money can only be used to fund research on drugs with ATV. A provision in the EU clinical trials framework, or national pricing and reimbursement policies, could have a similar effect.

Fundamentally, its potential for success depends upon the continual ability of entrepreneurial EU public health actors to work with large national health actors and European institutions to form an alliance that can continually pressure the European and global pharmaceutical industry to recognise the importance of public health needs and interests. Maintaining this alliance over a longer period of time is the best way to make certain that any form of EU MNC will have a significant and long term impact in the evolving labyrinth of EU health policy.

\section{Acknowledgements}

This paper is based on a project commissioned by Wemos and undertaken by the European Public Health Alliance. The authors would like to thank Annelies den Boer, Leonardo Palumbo and Zoltán Massay-Kosubek for their input into the original project and their kind support in its further development.

\section{Bibliography}

Abraham, J. and Lewis, G. (2000), Regulating medicines in Europe: competition, expertise and public health, Routledge: London.

AIFA (Italian Medicines Agency) (2007), Criteria for ranking therapeutic innovation of new drugs, Working Group on Innovative Drugs working paper, approved 10 July 2007, available at: http://www.agenziafarmaco.gov.it/allegati/integral_document.pdf.

Andrew, M., Jøldal, B., and Tomson, G. (1995), ‘Norway’s national drug policy: its evolution and lessons for the future', in Hamrell, S. and Nordberg, O. (eds), Development Dialogue: 
Making National Drug Policies a Development Priority, available at http://apps.who.int/medicinedocs/documents/s19175en/s19175en.pdf, accessed October 2014.

Angell, M. (2004), The truth about drug companies: how they deceive us and what to do about it, Random House: New York.

Brooks, E. and Geyer, R. (2015), 'Whatever happened to the Norwegian Medical Need Clause? Lessons for current debates in EU pharmaceutical regulation.' (unpublished article).

Buko Pharma (2013), Pharma Brief, Number 8-9, November 2013.

European Commission (2007), From assessing innovative value of pharmaceuticals to pricing and reimbursement decisions, Pharmaceutical Forum Working Group on Pricing and Reimbursement, Brussels: European Commission.

European Medicines Agency (EMA)

(2015), Monthly statistics report: December 2014, EMA/22984/2015, 23 January 2015.

European Parliament (2011), Differences in costs of and access to pharmaceutical products in the EU, Study by the Directorate General for Internal Policies, Brussels: European Parliament.

Garattini, J. (1997), ‘Are me-too drugs justified?’, Journal of Nephrology, 10(6), 283-294.

Garattini, J. and Bertele, V. (2004), 'The role of the EMEA in regulating pharmaceutical products', in Mossialos, E., Mrazek, M. and Walley, T. (Eds), Regulating pharmaceuticals in Europe: striving for efficiency, equity and quality, Open University Press: Berkshire.

Garattini, J. and Bertele, V. (2007), 'Non-inferiority trials are unethical because they disregard patients’ interests’, The Lancet, 379(9602), 1875-1877. 
Håkonsen, H., Horn, A. and Toverud, E. (2009), 'Price control as a strategy for pharmaceutical cost containment - what has been achieved in Norway in the period 19942004', Health Policy, 90, 277-85.

Hancher, L. (1990), ‘The European pharmaceutical market: problems of partial harmonisation', The European Law Review, 9.

Hawkes, N. (2014), 'NICE to set out how it will judge social benefits of drugs', British Medical Journal, 348:g370, 1-2.

Hervey, T. (2001), ‘Mapping the contours of European Union health law and policy’, Paper given for the ECSA Seventh Biennial International Conference, 31 May to 2 June 2001, Madison, Wisconsin.

Hervey, T. and McHale, J. (2004), Health law and the European Union, Cambridge University Press: Cambridge.

Hollis, A. (2004), Me-too drugs: is there a problem?, Briefing Note, World Health Organisation: Copenhagen.

ISDB (International Society of Drug Bulletins) (2001), Declaration on therapeutic advance in the use of medicines, Paris 15-16 November 2001.

Jøldal, B. (1986), 'The evaluation and control of drugs in Norway', International Journal of Technology Assessment in Healthcare, 2, 663-72.

La Revue Prescrire (2002), 'Drugs in 2001: A number of Ruses unveiled’ Editorial in Prescrire International, 11 Number 58, 58-60.

La Revue Prescrire (2012), ‘New drugs and indications in 2011’ Editorial in Prescrire International, 21 Number 126, 106-110. 
Light, D. and Lexchin, J. (2012), 'Pharmaceutical research and development: what do we get for all that money?', British Medical Journal, 344:e4348, 1-5.

Light, D., Lexchin, J. and Darrow, J. (2013), ‘Institutional corruption of pharmaceuticals and the myth of safe and effective drugs', Journal of Law, Medicine and Ethics, Fall 2013, 2-12.

Lu, Y., Hernandez, P., Abegunde, D. and Edejer, T. (2011) The world medicines situation 2011: Medical expenditures, World Health Organisation: Geneva.

Morgan, S. et al. (2005), 'Breakthrough drugs and growth in expenditure on prescription drugs in Canada’, British Medical Journal, 331:815, 1-2.

Nathan, C. (2007), ‘Aligning pharmaceutical innovation with medical need’ Nature Medicine, 13(3), 304-308.

Norris, P. (1998), ‘The impact of European harmonisation on Norwegian drug policy’ Health Policy, 43, 65-81.

OECD (2013), ‘Pharmaceutical expenditure’, in OECD, Health at a Glance 2013: OECD Indicators, OECD Publishers: Paris.

OECD (2011), “'Pharmaceutical expenditure’, in OECD, Health at a Glance 2011: OECD Indicators, OECD Publishers: Paris.

Paris, V. and Belloni, A. (2013), 'Value in Pharmaceutical Pricing’, OECD Health Working Papers, Number 63, available at http://dx.doi.org/10.1787/5k43jc9v6knx-en.

Raftery, J. (2013), 'Value-based pricing : can it work?’, British Medical Journal, 347:f5941, $1-4$.

Raftery, J. (2014), 'Sofosbufir for hepatitis C - moving to country specific prices’, British Medical Journal Blog, published online 20 August 2014. 
Simon, R. (2000), ‘Are Placebo-Controlled Clinical Trials Ethical or Needed When Alternative Treatment Exists?’, Annals of Internal Medicine, 133(6), 474-475.

Vitry, A., Shin, N. and Vitre, P. (2013), 'Assessment of the therapeutic value of new medicines marketed in Australia', Journal of Pharmaceutical Policy and Practice, 6(2), 1-6.

Wemos (2013), The clinical trials industry in South Africa: Ethics, rules and realities, available at:

http://www.wemos.nl/files/Documenten\%20Informatief/Bestanden\%20voor\%20\%27Medicij nen\%27/Clinical_Trials_Industry_South_Africa_2013_v3.pdf

Wieseler, B. (2011), 'How, and on whose behalf, should the ‘added therapeutic value’ of a new drug be assessed?' Pilule d'Or Prescrire, conference debate, available at:

http://www.prescrire.org/Docu/Archive/docus/WieselerENPiluleOrPrescrire2011.pdf.

Wilson, J. (1980), The Politics of Regulation, Basic Books: New York.

Wise, J. (2013), 'NHS spending on drugs is frozen for two years under price deal', British Medical Journal, 347:f6731, 1. 